\title{
Special Issue on Oxidation in Water Vapor
}

\author{
Sébastien Chevalier ${ }^{1} \cdot$ B. Pint $^{2} \cdot$ D. Monceau $^{3}$
}

Received: 20 December 2016/Published online: 18 January 2017

(C) Springer Science+Business Media New York 2017

There has been much effort over the years directed on elucidating the impact of water vapor on the high-temperature oxidation behavior of metallic materials. This is because most service conditions encounter a relatively high level of humidity or steam. The effect of water vapor on the oxidation behavior of metals and alloys can be positive or negative depending on many parameters, including substrate composition, water vapor content, presence of oxygen or not, exposure temperature, and flow conditions. As a consequence of there being so many variables, there is no apparent general rule for anticipating the effect(s) of water vapor on the oxidation resistance of metallic materials.

Chromia-scale forming materials are known to show beneficial effects in steam alone, but there is a negative effect when oxygen/air is present with water vapor, because of $\mathrm{Cr}$ species volatilization. Chromium content in the alloy or coating plays an important role, with an increase in content generally improving the oxidation resistance in water vapor. Much greater resistance can be realized with Al addition at an amount sufficient to form an alumina scale, which is less sensitive to water vapor-enriched atmospheres.

Sébastien Chevalier

sebastien.chevalier@u-bourgogne.fr

B. Pint

pintba@ornl.gov

D. Monceau

daniel.monceau@ensiacet.fr

1 ICB, UMR 6303 CNRS, Université Bourgogne Franche-Comté, 9 Avenue A. Savary, BP 47870, 21078 Dijon Cedex, France

2 Materials Science and Technology Division, Oak Ridge National Laboratory, Oak Ridge, TN 37831-6156, USA

3 INP Toulouse-CNRS CIRIMAT, 31030 Toulouse, France 
Coatings can be used to protect alloys from water vapor. Slurry coatings, able to form aluminides, or $\mathrm{CrN} / \mathrm{NbN}$ PVD coatings have evidenced promising results even after $2000 \mathrm{~h}$ of exposure in steam at $650{ }^{\circ} \mathrm{C}$. The use of model systems (without minor element addition) helps to better understand and isolate oxidation mechanisms.

Recent research efforts have been focused on the behavior of alloys in a nuclear environment, particularly when an accidental and abrupt increase in temperature is observed in nuclear power plants. This concerns FeCrAl steels but also zirconium alloys, such as zircaloy. The studies are conducted using ultra-high-temperature conditions, leading to catastrophic oxidation behavior for which water vapor plays a crucial role.

All studies cover several disciplines from high-temperature reactivity to surface preparation, passing through mechanical behaviors (creep and stress) and characterizations of corrosion products (Raman, TEM, XRD, etc.). And all approaches aim to increase the lifetime in severe conditions at high temperature and to better understand oxidation behavior in water vapor.

The following key papers were presented at the 9th international conference on High Temperature Corrosion and Protection of Materials (HTCPM2016), which was held at Les Embiez Island, France, on the 15-20th of May 2016. 